\title{
История автоматизации одного процесса, или как оцифровать ручное производство
}

\author{
д. Чернов ${ }^{1}$
}

УДК 658.5 | ВАК 05.13 .06

\begin{abstract}
Принципы четвертой промышленной революции («Индустрии 4.0») находят всё большее отражение в современном российском приборостроении. Темпы цифровизации отрасли могли бы быть интенсивнее, и государство активно стремится поддерживать разработку и внедрение инновационных решений, что, безусловно, дает свои плоды. Различные исследования говорят о том, что автоматизация уже глубоко проникла в некоторые сферы промышленного производства, например, в бухгалтерском учете российской радиоэлектронной промышленности она достигает 100\%, а в складских процессах и документообороте уже превышает 50\%. К сожалению, доля автоматизации бизнес-процессов, отражающих отраслевые особенности, существенно ниже. Решая задачу увеличения производительности, ООО “Остек-СМТ» создало новый продукт - "Умное рабочее место», направленный на повышение эффективности ручного труда.
\end{abstract}

$\mathrm{P}$ оссийское приборостроительное производство имеет свою четко выраженную специфику, которая обусловлена большим количеством технологических операций, выполняемых исключительно вручную. Это связано с несколькими факторами: компонентной базой, технологическими процессами производства, утвержденными государственными и отраслевыми стандартами и т.д. Некоторые предприятия отрасли имеют в своем штате тысячи сотрудников, выполняющих ручные операции пайки, монтажа, сборки и прочие.

Оперативное управление таким производством - это функционал MES-системы предприятия. Но наша действительность такова, что либо на предприятии еще не внедрена MES-система, либо она не доходит до уровня рабочего места. И в том и в другом случае участок выполнения ручных операций - это информационная «черная дыра", данные из которой поступают крайне скудно, медленно и точно не в режиме реального времени.

\section{РОЖДЕНИЕ ИДЕИ}

За годы сотрудничества с нашими клиентами мы обнаружили целый ряд проблем, связанныхс производительностью ручного труда, технологической дисциплиной и прослеживаемостью. Непроизводственные затраты времени работников поражают, значения достигают 30\% рабочего времени. При производстве микроэлектроники бумажная документация на рабочих местах упаковывается

ООО «Остек-СМт», руководитель направления автоматизации рабочих мест в полиэтиленовые пакеты, чтобы бумажная пыль не распространялась по чистому помещению. Фактическая трудоемкость всем крайне интересна, но никто не обладает реальной информацией о ней, поскольку над каждым монтажником невозможно засечь секундомер, а иных инструментов нет. Пооперационный учет, партионный учет используемых покупных комплектующих изделий (ПКИ), соблюдение технологии производства зачастую вызывают у заказчиков мечтательно-скептическое выражение лица.

Перед нами встала весьма амбициозная задача, которая нас очень заинтересовала. После проведения дополнительных исследований мы занялись созданием концепта решения, которое в последующем получило название "Умное рабочее место". Были сформулированы алгоритмы учета ручных операций, подсчета выработки, контроля технологического процесса производства, описаны принципы взаимодействия сотрудника с интерфейсом, разработана логика движения изделия через систему. При этом наше творчество не знало границ. Система идентифицировала сотрудника по технологии распознавания лиц, визуально контролировала пропуски и ошибки при установке компонентов, управляла световой индикацией на рабочем месте в зависимости от статуса и ситуации на нем.

Готовый концепт был представлен Остек-СМТ в 2018 году на 17-й Международной выставке технологий, оборудования и материалов для производства изделий электронной и электротехнической промышленности «ЭлектронТехЭкспо" (рис. 1). Презентация вызвала живой интерес 


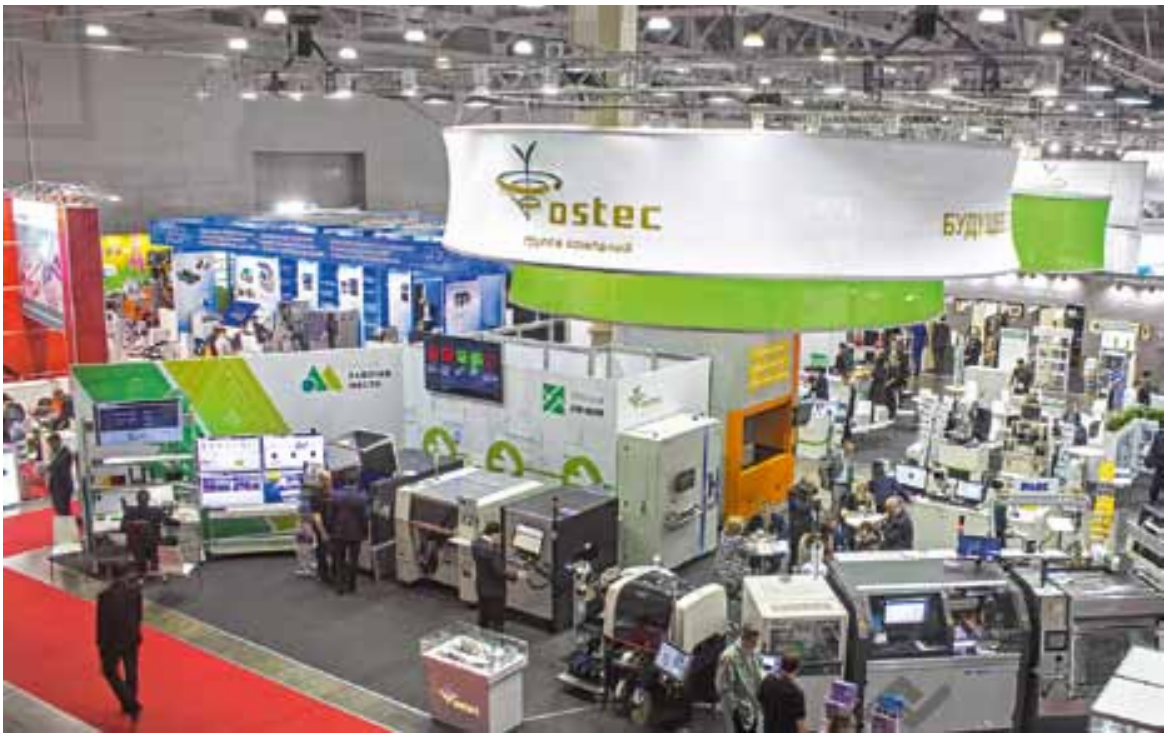

Рис. 1. Стенд Группы компаний Остек на выставке “ЭлектронТехЭкспо-2018»

и поступают в экспертный модуль «Умной линии», где проводится их анализ и обработка. Экспертный модуль в режиме реального времени транслирует обработанную информацию получателям.

По итогам выставки "ЭлектронТехЭкспо-2018» собственная команда разработчиков Остек-СМТ была расширена и наряду с «Умной линией» занялась разработкой программноаналитического комплекса "Умное рабочее место".

Первой решенной задачей стал уход от бумажной документации на рабочем месте монтажника (рис. 2). Форматы от А4 до А0 перекочевали на сенсорный монитор, который позволяет увеличивать и перемещать чертеж по экрану, как при просмо-

отрасли. Ажиотаж вокруг концепта не утихал в течение всего времени работы выставки. По мнению ряда руководителей крупных предприятий, решение задачи является актуальным для организаций оборонно-промышленного комплекса Российской Федерации.

\section{ОТ КОНЦЕПТА \\ К ДЕЙСТВУЮЩЕМУ ПРОИЗВОДСТВУ}

Решая задачу максимального распространения принципов "Индустрии 4.0» и обеспечения высокой эффективности производственного процесса в приборостроительной отрасли, Остек-СМТ с 2015 года ведет разработку и внедрение пакета решений, ориентированного на комплексный подход. В рамках модернизации сборочномонтажных производств и автоматизированных конвейерных линий реализуется концепция "Умная линия" и ведутся разработка и развитие одноименного программного продукта. Продукт анализирует, обрабатывает и представляет цифровую информацию персоналу, управляющему производством. "Умная линия» в части функционала является примером импортозамещения зарубежных аналогов, ориентированных на решение аналогичных задач, но имеет ряд существенных отличий, учитывающих специфику предприятий Российской Федерации, в том числе в области информационной безопасности. В процессе эксплуатации данные, получаемые с оборудования, структурируются

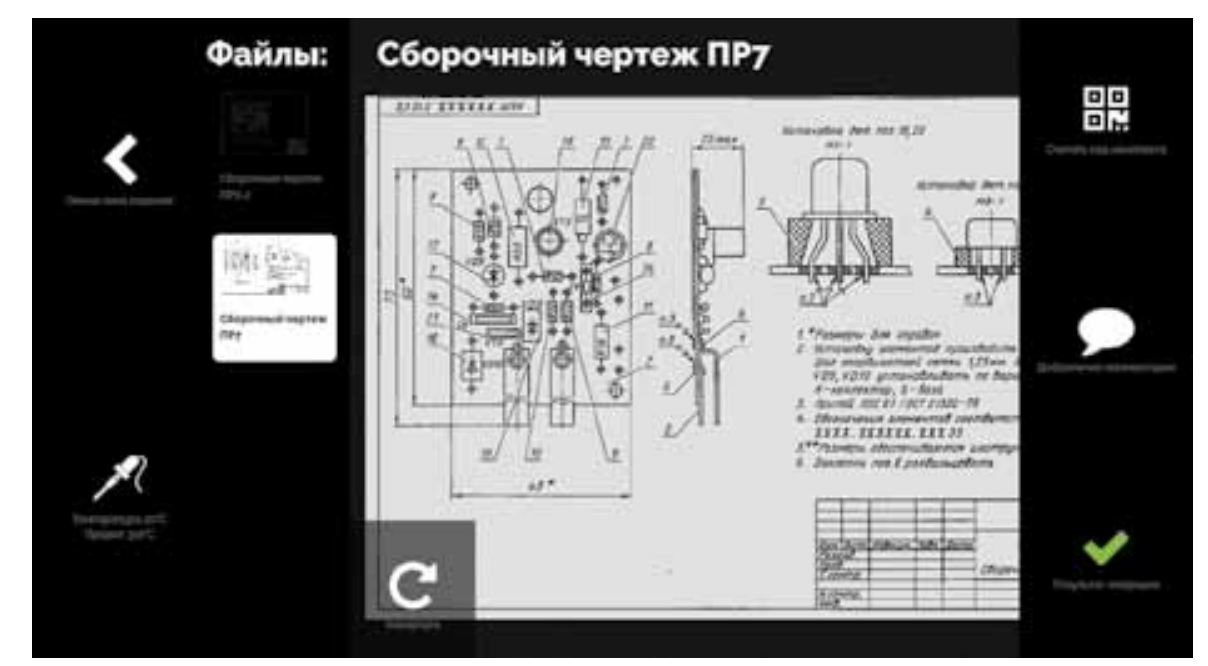

Рис. 2. Отображение документации на рабочем месте тре фотографии на смартфоне. Монитор дает возможность просматривать документы в формате АЗ без увеличения, что с учетом тенденции перехода предприятий к операционным картам покрывает бо́льшую часть выполняемых операций. При этом миникомпьютер и монитор, которыми оснащается рабочее место, являются лишь средствами сбора и отображения информации. Хранение и обработка всех документов и данных проводятся на центральном сервере "Умного рабочего места». Вместе с этим была решена и задача актуализации документации на рабочих местах, теперь технолог проводит извещение об изменении только в одном месте - на сервере "Умного рабочего места», а доставка документации сотрудникам производится автоматически. 
Сделав труд монтажника несколько легче и повысив эргономику его рабочего места за счет освобождения значительного пространства на поверхности стола, мы перешли к автоматизации учета. Главным на этом этапе было не создать монтажнику дополнительной работы. Действий, связанных с учетом, как минимум не должно было стать больше. В результате появился механизм, во многом повторяющий бумажный технологический паспорт, который сопровождает изделие в процессе производства. Окончив операцию, сотрудник фиксирует это на мониторе, и информация в режиме реального времени заносится в базу данных и отображается на диспетчерском экране руководителя. Окончание финальной операции с изделием означает выход готового изделия и соответствующее увеличение счетчика готовой продукции на диспетчерском экране (рис. 3).

Главным отличием цифрового клона от бумажного технологического паспорта стала фиксация не только даты окончания операции, но и даты ее начала, а также времени обоих событий. Зная, когда началась и когда закончилась операция, можно определить ее фактическую трудоемкость. Сложив трудоемкости всех операций по изделию, мы получаем фактическую трудоемкость изделия в целом. Эта информация открывает обширные горизонты для оптимизации и контроля. Почему готовое изделие выходит с участка через четыре дня с момента запуска в производство, если его фактическая трудоемкость равна 6,5 4? Почему изделие пролежало два дня между соседними операциями? Почему норма на операцию составляет 2,5 ч, если фактически операция выполняется 4 4? Оцифрованная информация с участка увеличивает производительность труда сотрудников, повышает управляемость производства, дает руководителю инструмент контроля в режиме реального времени.
Заполненный на каждой операции цифровой клон технологического паспорта в последующем получил логичное название "Цифровой паспорт». Формат этого документа может быть любым. Как правило, он повторяет форму технологического паспорта, принятого на предприятии, в заголовке он содержит наименование и номера изделия, а в каждой строке - информацию о наименовании операции, исполнителе, датах и времени начала и окончания операции, статусе ее выполнения.

Дополнительно к этому "Цифровой паспорт» может содержать информацию о температуре жала паяльника, при которой выполнялась пайка того или иного изделия. Как показал опрос заказчиков, несоблюдение технологической дисциплины - одна из самых серьезных проблем при ручном производстве. Известно, что каждая операция пайки должна выполняться при определенной температуре жала паяльника, и эта температура прописана в технологической документации. Завышение температуры пайки улучшает паяемость и ускоряет работу, но увеличивает вероятность брака. Часто нанесенные таким образом повреждения невозможно обнаружить без специальных рентгеновских установок. В комплексе «Умное рабочее место" реализован автоматический контроль температуры жала цифровой паяльной станции. В случае превышения рекомендованной для данной операции температуры пайки «Умное рабочее место» информирует об этом монтажника или руководителя.

Возвращаясь к операциям, стоит отметить, что "Умное рабочее место" может контролировать последовательность выполнения операций, если она жестко задана. Также операция может получить статус «Приостановлено", например, при нехватке комплектующих для окончания монтажа. При пополнении дефицита такое изделие можно оперативно вернуть в производство на приостановленную операцию и продолжить монтаж. Причем операцию далее может выполнять другой сотрудник, что будет отражено в «Цифровом паспорте», также как и информация о выполнении операции до приостановки.

Любая автоматизация нацелена на повышение эффективности производства. В случае «Умного рабочего места» речь идет об эффективности работы сотрудников. Зная фактическую трудоемкость выполненной операции, всегда можно оценить работу сотрудника относительно нормы. Имея историю выполнения операций, можно сравнить сегодняшнюю работу сотрудника со вчерашней и оценить изменение

Рис. 3. Диспетчерский экран комплекса "Умное рабочее место» 
производительности. Эффект соревнования при выполнении одинаковых операций разными сотрудниками также может дать прирост производительности.

"Умное рабочее место" собирает информацию о производстве и выполняет мониторинг текущей ситуации. Всё, что собрано в базу данных, может быть предоставлено руководителю в виде всевозможных отчетов об эффективности производства, о выполнении плана, о выпущенной продукции и т. д. Отчеты могут направляться по электронной почте в соответствии с расписанием, а текущие оповещения - на смартфон или умные часы.

\section{ПЕРВОЕ ВНЕДРЕНИЕ}

Итоговый функционал, реализованный в «Умном рабочем месте», достаточно серьезно отличается от того, который был заложен в концепт, представленный на выставке в 2018 году. Опрос клиентов, который проводился и проводится до сих пор, показал, что ряд функций концепта является избыточным, при этом клиенты рассказали о том, какие функции наиболее востребованы на их предприятиях. На этом этапе огромную помощь и поддержку развитию "Умного рабочего места» оказал наш технологический партнер АО «Рязанский Радиозавод". Он стал первым предприятием отрасли, на производстве которого внедрено "Умное рабочее место». Реализация этого проекта закончена специалистами ОстекСМТ в октябре 2019 года.

АО «Рязанский Радиозавод" основано в 1953 году и является крупнейшим поставщиком средств связи для Министерства обороны Российской Федерации, Росгвардии, ФСО и других силовых структур страны. С 2007 года завод входит в состав АО «Концерн “Созвездие», который в свою очередь входит в ХК АО «Росэлектроника» Государственной корпорации «Ростех».

АО "Рязанский Радиозавод" производит средства радиосвязи пятого поколения, которые обеспечивают устойчивую помехозащищенную и разведзащищенную радиосвязь между различными подразделениями. Предприятие располагает широким спектром различных производств, в числе которых сборочное, механическое, пластмассовое, штамповочное, гальваническое, инструментальное, литье под давлением; является одним из ведущих в концерне и оснащено самым современным оборудованием. Инновационный подход руководителей предприятия к развитию завода основывается на самых современных методах производства и управления, включающих принципы «Индустрии 4.0" и бережливого производства.

Внедрение программно-аналитического комплекса "Умное рабочее место» на производстве АО «Рязанский Радиозавод" производилось в рамках проекта реконструкции действующего производственного цеха. Остек-СМТ оснастило все 66 рабочих мест обновленного цеха (рис. 4).
В комплект поставки вошла новая промышленная мебель производства Группы компаний Остек, светильники, антистатическое оснащение рабочих мест. На 20 рабочих мест было дополнительно установлено компьютерное оборудование для работы с комплексом «Умное рабочее место».

Помещение было предварительно отремонтировано, обновлены инженерные сети, включая систему вытяжной вентиляции, проложена структурированная кабельная сеть. После этого специалисты Остек-СМТ смонтировали и установили на места новые столы и стулья, подключили элементы антистатической защиты к новому контуру антистатического заземления, подключили и запустили компьютерное оборудование. Каждый этап требовал предварительной проработки, важно было создать максимально эргономичное рабочее место, в частности поэтому было принято решение разместить сенсорные мониторы не на поверхности стола, как это обычно бывает, а на настенном кронштейне. Это позволило сохранить свободной рабочую поверхность стола под монитором.

Настройка программной части комплекса "Умное рабочее место" началась задолго до установки оборудования в цехе АО «Рязанский Радиозавод". Предварительная работа включала подготовку электронной технологической и конструкторской документации, формирование и загрузку перечней операций, определение статусов для каждой операции и т.д.

В результате всех проведенных работ на предприятии развернута система, реализующая функции предоставления сотрудникам электронной документации, учета и контроля операций. К системе подключены монтажники, слесари-сборщики, регулировщики, диспетчер, начальники участка и цеха. Каждому сотруднику предоставлен свой интерфейс, соответствующий его правам

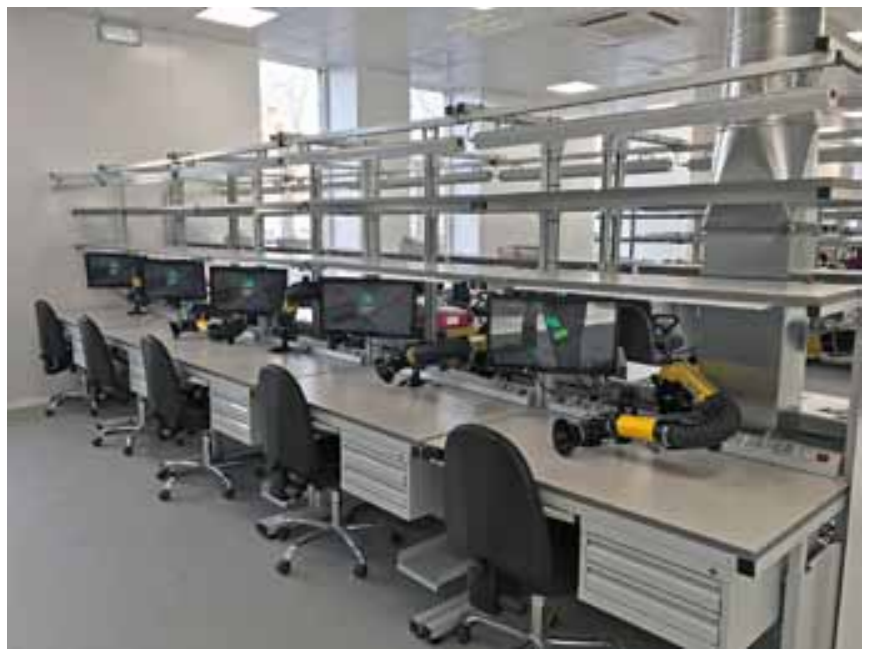

Рис. 4. Сборочно-монтажное производство АО "Рязанский Радиозавод" 
и задачам. Центральный диспетчерский экран размером 55" в режиме реального времени отображает информацию о выполнении текущего плана производства.

"Внедрение комплекса "Умное рабочее место» на сборочно-монтажном производстве завода позволит нам усилить контроль за производством, а также повысить качество и конкурентоспособность выпускаемой продукции", - говорит первый заместитель генерального директора - исполнительный директор АО «Рязанский Радиозавод" Алексей Сергеевич Широков.

Для обеспечения оперативного обмена производственными данными "Умное рабочее место" АО "Рязанский Радиозавод" интегрировано с существующей информационной системой управления производством Таким образом, все службы завода в оперативном режиме получают информацию о состоянии производства и выпущенной продукции.

В ближайшем будущем АО «Рязанский Радиозавод» рассматривает масштабирование решения "Умное рабочее место" на всё сборочно-монтажное производство, на котором занято более 100 сотрудников, выполняющих ручные операции. К этому моменту Остек-СМТ планирует существенно расширить функционал программно-аналитического комплекса "Умное рабочее место" за счет "умных помощников" и новых аналитических функций

\section{НОВЫЕ КНИГИ ИЗДАТЕЛЬСТВА "ТЕХНОСФЕРА»}

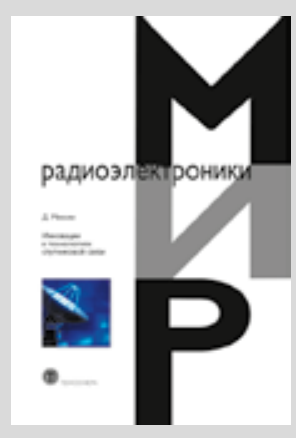

Цена 1188 руб.

\section{ИННОВАЦИИ В ТЕХНОЛОГИЯХ СПУТНИКОВОЙ СВЯЗИ}

\section{Миноли Д.}

\section{Издание осуществпено при поддержке Фипиапа ОАО «ОРКК» - «НИИ КП»}

Книга является обзором ключевых достижений в области коммерческой спутниковой связи. В ней ставится вопрос о том, какими могут быть новые возможности для конечных пользователей и поставщиков услуг в использовании новейших быстроразвивающихся инноваций в этой области (расширение спецификации DBV-S2 (DVS-S2X), технологий спутниковых каналов с высокой пропускной способностью (HTS, High throughput satellite), методов спутникого применения решений M2M (machine-to-machine) и т.д.).

Издание можно считать справочным пособием, так как в вводную главу включен справочный технический материал, который будет служить в качестве учебника по спутниковой связи для начинающих.

В русском переводе книги в подстрочных примечаниях раскрыто содержание некоторых использованных терминов из словаря программистов-компьютерщиков (веб-страницы, браузер, утилита, стек, хаб и др.).

Первое использование в книге аббревиатур на английском языке сопровождается переводом на русский язык, в дальнейшем в тексте аббревиатуры используются без пояснений. Для удобства читателей в издании на русском языке в приложении В приведен Глоссарий основных концепций и терминов спутниковой связи. 


\section{ИЗДАТЕЛЬСТВО «ТЕХНОСФЕРА» ПРЕДСТАВЛЯЕТ КНИГУ:}

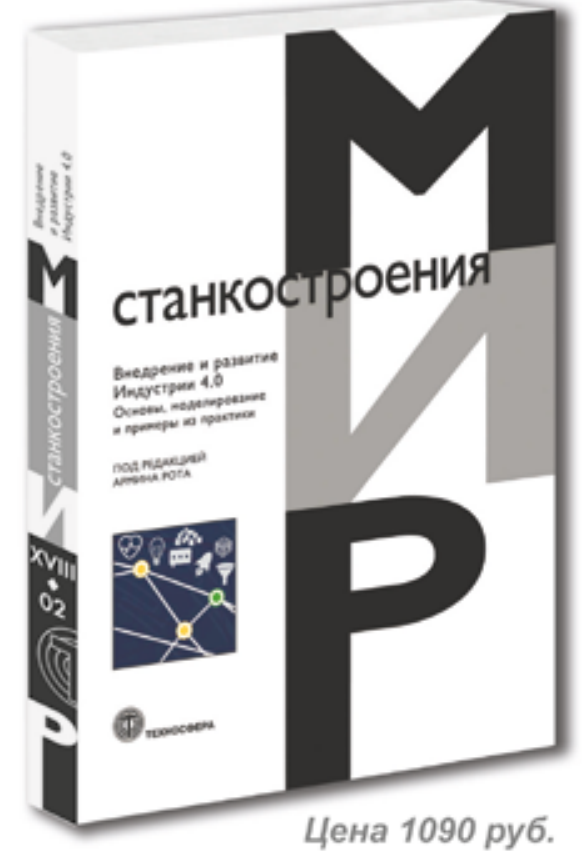

\section{ВНЕДРЕНИЕ И РАЗВИТИЕ ИНДУСТРИИ 4.0.}

Основы, моделирование

и примеры из практики

Под ред. Армина Рота

Пер. с нем. под общей ред. А.В. Кострова

M.: ТЕХНОСФЕРА, 2017. - 294 c.

ISBN 978-5-94836-482-7

Издание осуществлено при финансовой

поддержке ПАО «Ростелеком"

В книге представлены концепция, основные парадигмы развития, структура технологии Индустрии 4.0. В отличие от широко распространенного технократического прикладного метода изучения, издание позволяет выделить и целостно описать уровни стратегического, тактического и оперативного управления. Ключевым элементом при этом является процессная модель, описывающая действия на стратегическом и оперативном уровнях, а примеры практического применения Индустрии 4.0 в различных отраслях промышленности наряду с мнениями известных экспертов в области науки и производства вызовут интерес не только у новичков отрасли, но и у научных сотрудников, инженерно-технических работников и руководителей высшего и среднего звена.

Благодаря обширному глоссарию издание станет ценным справочным пособием по использованию основных положений и лучших практик Индустрии 4.0.

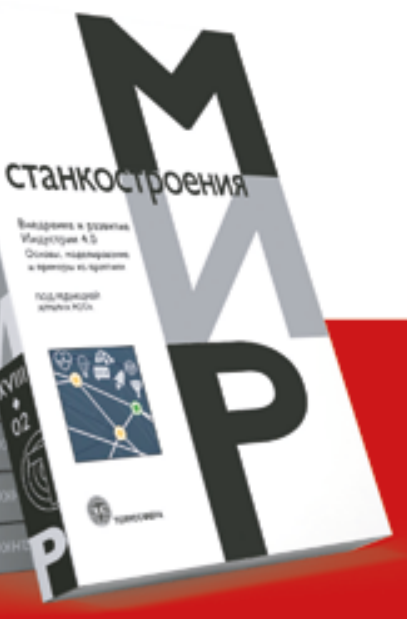

